\title{
Mild and severe udder cleft dermatitis-Prevalence and risk factors in Swedish dairy herds
}

\author{
L. Ekman, ${ }^{*} \dagger$ A.-K. Nyman, ${ }^{*}$ H. Landin, $\ddagger$ U. Magnusson, $\dagger$ and K. Persson Waller ${ }^{*}{ }^{1}$ \\ *Department of Animal Health and Antimicrobial Strategies, National Veterinary Institute, SE-75189, Uppsala, Sweden \\ †Department of Clinical Sciences, Swedish University of Agricultural Sciences, SE-75007, Uppsala, Sweden \\ ¥Växa Sverige, SE-10425, Stockholm, Sweden
}

\begin{abstract}
Udder cleft dermatitis (UCD) is an inflammatory skin condition affecting the anterior parts of the udder of dairy cows. The lesions may present as mild or severe skin lesions and have been associated with mastitis and digital dermatitis. The full etiology and pathogenesis are not understood and no large-scale studies have investigated prevalence and risk factors. Therefore, the main objectives of the study were to investigate the prevalence of mild and severe UCD in Swedish dairy herds and to identify risk factors associated with such lesions. We also wanted to investigate risk factors for all cases of UCD and to determine whether UCD increases the risk for mastitis and culling. A random sample of 100 freestall dairy herds were included in the study, and each herd was visited once. Cows were registered as having no, mild, or severe UCD. Additional cow and herd data were obtained via observations, interviews, and the Swedish Official Milk Recording Scheme. The data were analyzed using logistic regression models to identify risk factors for mild and severe UCD. In total, data from 3,479 cows in 99 herds were analyzed. The prevalence of mild and severe UCD was 19 and $9 \%$, respectively. Lesions were found in 98 of 99 herds but the within-herd prevalence of mild $(0-43 \%)$ and severe (0-33\%) UCD varied notably between herds. Breed (Swedish Red compared with Swedish Holstein), certain udder conformation traits, and higher parity were risk factors associated with increased risk of UCD. In addition, cows with hock lesions and cows in herds with high incidence of culling due to hoof and leg diseases had a higher risk for mild UCD. More days in milk and high milk yield were cow-related risk factors associated with severe UCD. Three housing-related factors (shorter cubicles, mattress as cubicle base, and cubicles installed before 2001 compared with 2001-2005), a high incidence of veterinary-treated clinical mastitis
\end{abstract}

Received May 9, 2017.

Accepted September 4, 2017.

${ }^{1}$ Corresponding author: karin.persson-waller@sva.se and culling due to udder diseases, and a low incidence of culling of first-parity cows in early lactation were herd-related risk factors associated with increased risk for severe UCD. In addition, cows in herds with a high proportion of heifers older than 17 mo that were not inseminated were associated with lower risk of all UCD. Finally, UCD was not associated with the outcomes milk somatic cell count, veterinary-treated clinical mastitis, or culling in the multivariable analyses. The etiology of UCD is most likely multifactorial, involving udder conformation traits and other cow-related risk factors as well as herd-related risk factors. The high prevalence of severe UCD lesions in Swedish dairy cows emphasizes the need for preventive measures and efficient treatments.

Key words: udder cleft dermatitis, dairy cow, ulcerative mammary dermatitis, intertrigo

\section{INTRODUCTION}

Udder cleft dermatitis (UCD) in dairy cows is an inflammatory skin condition in the anterior junction between the udder and the abdominal wall, or between the front quarters of the udder. The condition is also known as ulcerative mammary dermatitis or intertrigo, and has been reported in several countries (Warnick et al., 2002; Olde Riekerink et al., 2014; Persson Waller et al., 2014). Udder cleft dermatitis lesions may differ in severity, and some develop into deep exudative ulcers, impairing the welfare of affected cows. The lesions can contain a variety of bacteria (Warnick et al., 2002; Persson Waller, 2003), indicating a possible link between UCD and infectious diseases such as mastitis. In line with this, Persson Waller et al. (2014) found a higher risk for clinical mastitis in cows with UCD.

Although UCD has been reported in selected herds (Beattie and Taylor, 2000; Warnick et al., 2002; Hansen and Nissen, 2010), only 2 studies have investigated the prevalence in randomly selected dairy herds (Olde Riekerink et al., 2014; Persson Waller et al., 2014). In these studies, the average within-herd prevalence of UCD was 18\% (range 0-39\%; Persson Waller et al., 
2014) and 5\% (range 0-15\%; Olde Riekerink et al., 2014). As there is no common definition of UCD, comparisons between studies must be made with caution. Recent studies, however, have categorized UCD lesions as mild (mostly undisrupted skin integrity) or severe (mostly involving open wounds) using similar criteria (Persson Waller et al., 2014; Bouma et al., 2016). Previous studies on the prevalence of UCD (Olde Riekerink et al., 2014; Persson Waller et al., 2014) have included only a limited number of herds. This, together with the large between-herd variation in prevalence of mild and severe UCD lesions, warrants investigation of a larger number of randomly selected herds.

The etiology and pathogenesis of UCD are largely unknown, despite the identification of some cow- and herd-related risk factors. Certain udder conformation traits (e.g., loose fore udder attachment or a deep udder) increase the risk of UCD (Hansen and Nissen, 2010; Olde Riekerink et al., 2014; Persson Waller et al., 2014). Other cow-related risk factors include breed (Persson Waller et al., 2014), higher parity (Warnick et al., 2002; Persson Waller et al., 2014), higher DIM (Bouma et al., 2016), and high milk yield (Hansen and Nissen, 2010). Infectious agents such as treponemes (Boyer and Singleton, 1998) and mange mites (Allenstein, 1991) have been suggested to cause, or worsen, UCD lesions, although not all studies support this (Warnick et al., 2002; Hansen and Nissen, 2010; Persson Waller et al., 2014). At the herd level, risk factors associated with UCD are breed (high proportion of Swedish Red cows) and high production (Olde Riekerink et al., 2014; Persson Waller et al., 2014). Nevertheless, risk factors in previous studies explain only a small part of the variation in UCD prevalence (Olde Riekerink et al., 2014; Persson Waller et al., 2014), indicating that other factors may exist. Moreover, these studies did not take into account the degree of UCD severity. For example, risk factors for hock lesions (HL) in dairy cows are known to vary depending on severity of lesion (Potterton et al., 2011). Given the results of these previous studies on UCD and HL, separate modeling of risk factors for mild and severe UCD lesions is warranted.

Prevention of UCD lesions is important because these lesions may be common in dairy herds and they have a negative effect on animal welfare. Large-scale studies on prevalence and risk factors for UCD are needed to improve recommendations for prevention and to better understand the epidemiology of UCD lesions of different severity. The main aims of our study were to investigate the prevalence of mild and severe UCD in freestall dairy herds in Sweden, and to identify cow- and herd-related risk factors associated with mild and severe UCD. We also wanted to investigate risk factors for all cases of
UCD. In addition, we investigated whether UCD was associated with increased risk for mastitis and culling.

\section{MATERIALS AND METHODS}

\section{Herd Selection}

A total of 100 randomly selected Swedish dairy herds were enrolled in a cross-sectional study using the following criteria: freestall housing, herd size of 50 to 210 cows, herringbone or tandem milking parlor, and affiliation with the Swedish Official Milk Recording Scheme (SOMRS). The sample size was calculated by use of the formula $\mathrm{n}=\left[\mathrm{Z}^{2} \times \mathrm{P}(1-\mathrm{P})\right] / \mathrm{e}^{2}$, where $\mathrm{Z}=1.96$, the estimated true prevalence $(\mathrm{P})$ was 20 to $30 \%$, and the precision (e) was set to $10 \%$, which gave a sample size of 60 to 80 herds. Because of the risk of herds quitting the study, the sample size was set to 100 herds. Participating herds were in the southern half of Sweden, where $90 \%$ of herds meeting the inclusion criteria are located. A letter about the project was sent to all eligible herd owners $(\mathrm{n}=961)$, after which they were contacted via telephone until a representative sample of 100 herds (based on dairy production density in each county) agreed to participate. In total, 197 herds were contacted, 64 of which were excluded because they had changed to an automatic milking system or used a parallel milking parlor. Thirty herds declined to participate in the study. Reasons given were no interest in the study (12 herds), lack of time (10 herds) or the farmer had quit or was going to quit dairy production (8 herds). Of the remaining 103 herds, 1 was later excluded as most of the cows were milked in an automatic milking system, and 2 herds were not visited due to logistical reasons.

\section{Data Collection}

Each herd was visited during one milking (morning, midday, or evening) in the winter housing season; that is, February to April 2014 (39 herds) or December to March 2014-2015 (61 herds). All visits and registrations were performed by the first author. Additional cow and herd data were obtained from the SOMRS.

\section{Cow Data}

A detailed list of collected cow-related variables ( $\mathrm{n}=$ 19) and how they were obtained is given in Supplemental Table S1 (https://doi.org/10.3168/jds.2017-13133). During milking, every second to third cow entering the milking parlor was examined for UCD, udder conformation, hygiene, and presence of HL. Most cows were 
examined within 1 to 2 min before or after attachment of the milking unit. The cows were registered as having no UCD (i.e., no visual or palpable skin damages), mild UCD (i.e., hyperkeratosis, small papulae/pustulae, small crusts, or serum transudation), or severe UCD (i.e., pus, deep skin wounds, or proliferations with or without findings of mild UCD) as previously described (Persson Waller et al., 2014), except that the presence of large crusts was categorized as severe UCD. A handheld mirror and a flashlight were used when inspecting the udders, and fresh disposable gloves were used for each cow to minimize spread of infections. Three udder conformation traits were registered: fore udder attachment (angle between fore udder and abdominal wall), udder balance (depth of the rear udder in relation to depth of the front udder), and presence or not of an indentation or skin fold $(\mathbf{I} / \mathbf{F})$ at the anterior junction between the udder and the abdominal wall, as previously described (Persson Waller et al., 2014). The hygiene of the cows was scored based on the cleanliness of the udder and the hind limb above the hock on the side visible from the operating area. Hygiene scores ranged from 1 to 4 , where $1=$ completely clean, $2=$ manure stains on hind limb or udder, $3=1$ or 2 areas of manure patches of at least $10 \mathrm{~cm}$ in diameter, and $4=$ more than 2 areas of manure patches as described for score 3 (modified from Cook and Reinemann, 2007). Presence of HL scored as mild (hair loss) or severe (skin wound or evident swelling) on the outside of the hock visible from the operating area was also recorded using the Hock Assessment Chart for Cattle (Cornell University, Ithaca, NY).

Individual cow data on breed, parity, and DIM at the time of the visit were obtained from the SOMRS, as was information on individual milk yield $(\mathrm{kg} / \mathrm{d})$, cow composite milk SCC, and milk urea concentrations at test milkings within $34 \mathrm{~d}$ before or after the visit. Registrations of veterinary-treated diseases within 90 $\mathrm{d}$ and results from hoof trimmings within 6 mo before or after the visit were collected from the SOMRS when available, as well as information on culling of the cow within $90 \mathrm{~d}$ after the visit.

\section{Herd Data}

A detailed list of collected herd-related variables and how they were obtained is given in Supplemental Table S2 (https://doi.org/10.3168/jds.2017-13133). Table 1 presents an overview of herd-related variables analyzed for associations with UCD ( $\mathrm{n}=67)$, grouped by general herd factors, housing-related factors, managementrelated factors, and herd health-related factors. In each herd, milking routines, housing-related factors, and other management-related factors were registered through observation or from interviews with the farmer or staff. Additional herd information was obtained from the SOMRS, including herd performance indicators, for the 12 mo preceding the herd visit. These herd performance indicators, designed by one of the Swedish dairy farmer organizations (Växa Sverige, Stockholm, Sweden), include calf and cow mortality, incidence of culling and veterinary-treated diseases, percentage of cows with abnormal milk urea concentrations, and fertility traits.

\section{Data Editing and Statistical Analyses}

Cow and herd data registered in hand-written, onfarm protocols were transferred to Excel spreadsheets (Microsoft Corp., Redmond, WA). The data were imported to Stata (release 13.1; StataCorp LP, College Station, TX) after double-checking by a second individual that the transfer of data from the protocols was correct. All statistical analyses were performed using Stata. The prevalence of mild, severe, and overall UCD lesions among all examined cows, and within each herd, was calculated.

Risk Factors for UCD. Associations between the presence of mild UCD and explanatory variables were analyzed in univariable mixed-effect logistic regression

Table 1. Herd-related variables analyzed for associations with udder cleft dermatitis (UCD) in 99 Swedish dairy herds

\begin{tabular}{|c|c|c|}
\hline General herd factors & 4 & Herd size (cows/yr), production system, milk production, slaughter weights \\
\hline Housing-related factors & 17 & $\begin{array}{l}\text { Cubicle dimensions, year of cubicle installation, cubicle base and bedding material, stocking } \\
\text { rate (cubicles/cow) }\end{array}$ \\
\hline Management-related factors & 19 & Pasture period, cubicle and alley cleaning, hoof trimming, milking, and feeding routines \\
\hline
\end{tabular}

${ }^{1}$ Based on herd performance indicators from the Swedish Official Milk Recording Scheme for the 12 mo preceding the herd visit. 
or mixed-effect linear regression models at the cow level with herd as a random factor using an identity covariance structure (equal variances for random effects, all covariances are zero). Cows with severe UCD were excluded from the analyses of risk factors for mild UCD. Associations between explanatory variables and severe UCD were analyzed in the same way, excluding cows with mild UCD. In addition, a model was made to investigate associations between all UCD and the explanatory variables. In total, 18 cow-related variables and 67 herd-related variables were analyzed for their association with mild, severe, and all UCD. Continuous variables were assessed if they were linearly related to the outcome; if not, they were categorized using percentiles as cut-offs or transformed using the natural logarithm. All variables with a $P$-value $\leq 0.20$ were further analyzed in multivariable, mixed-effect logistic regression models with herd as random factor.

Because of the large number of explanatory variables, 4 separate multivariable mixed-effect logistic regression sub-models were constructed for each of the outcomes (mild, severe, and all UCD). The variables included cow-related variables (Supplemental Table S1; https:// doi.org/10.3168/jds.2017-13133), as well as herd-related variables divided into general herd and housing-related, management-related, and herd health-related (Supplemental Table S2). Collinearity between variables was tested for all multivariable models by calculation of Spearman rank correlations. If variables showed collinearity $(r \geq 0.7)$, only the variable with the lowest $P$-value in the univariable analysis was kept in the model. Thereafter, models were built using a manual stepwise, backward variable selection procedure where the initial model included all independent variables as main effects. Variables with a significant association $(P$ $\leq 0.05)$ with the dependent variable were kept in the models. Visit period (February-April 2014 or December-March 2014/2015) was included in all multivariable models as a potential confounder. Cows with missing data for a specific explanatory variable were omitted when that variable was in the model. Two herds left the SOMRS shortly before or after the visit and were therefore excluded in the multivariable analyses due to missing data.

A final, multivariable mixed-effect model for each outcome (mild, severe, and all UCD) was then built using a manual, stepwise backward variable-selection procedure, including the variables that were significant $(P \leq 0.05)$ as main effects in the sub-models. Variables with a significant association $(P \leq 0.05)$ with the dependent variable were kept in the final models. All variables with $P \leq 0.20$ for mild, severe, or all UCD in the univariable analyses were then retested in the respective final model and kept in the model if they were significantly associated with the dependent variable. All plausible 2-way interactions between the significant main effects were tested in the final models. Model fit was assessed by visual examination of residual plots according to Hosmer and Lemeshow (2000) and Dohoo et al. (2010).

Associations Between UCD and Mastitis and Culling. In addition to identifying risk factors affecting the prevalence of UCD, we hypothesized that UCD lesions might influence udder health and possibly culling. To investigate such associations, we carried out univariable, mixed-effect logistic regression or mixed-effect linear regression analyses with mild UCD as explanatory variable for 3 cow-level outcomes: (1) milk SCC from test milking within $34 \mathrm{~d}$ before or after the visit (transformed using the natural logarithm to achieve normal distribution); (2) veterinary-treated clinical mastitis (VTCM) within $90 \mathrm{~d}$ before or after the visit; and (3) culling of the cow within $90 \mathrm{~d}$ after the visit, with herd included as random factor. If there was a significant association $(P \leq 0.05)$ between mild UCD and the dependent variable, then parity, breed, DIM, milk yield, and visit period were added to the model to investigate for confounding effects. Data were then analyzed in a multivariable mixed-effect logistic model to see if mild UCD was still significant after inclusion of the potential confounding factors. Only variables with a confounding effect on mild UCD (indicated by a change of $>20 \%$ in the point estimate of the coefficient) were kept in the final model. Collinearity between variables was tested for all multivariable models by calculation of Spearman rank correlations. The same procedure was used to test the outcomes for associations with severe UCD and all UCD. Model fit for all models was assessed by visual examination of residual plots according to Hosmer and Lemeshow (2000) and Dohoo et al. (2010).

\section{RESULTS}

\section{Herd and Cow Characteristics}

The mean annual herd size for participating herds was 106 cows (SD 41.6; range 49-223 cows) and the mean annual milk production was $9,914 \mathrm{~kg}$ of ECM/cow-year (SD 1,236 kg; range 6,277 to $13,225 \mathrm{~kg}$ ). The mean herd SCC was 247,000 cells/mL (SD 78,000; range 103,000523,000 cells $/ \mathrm{mL}$ ). Information on milk production and mean SCC was obtained from the SOMRS and based on the 12 mo preceding the herd visit. In total, 3,755 cows were examined [mean 38 cows/herd (SD 12.2); range 17-68 cows/herd], including 1,901 Swedish Holstein (SH), 1,300 Swedish Red (SR), 289 cross-breeds $(\mathrm{SH} \times \mathrm{SR})$, and 265 cows of other breeds (mainly Jersey). There were few cows of other breeds in the herds, 
except for one herd with only Jersey cows; therefore, cows of other breeds were excluded from the statistical analyses, including the exclusively Jersey herd. In addition, 11 cows were excluded because they were too dirty for assessment of UCD status. Thus, 3,479 cows from 99 herds were included in the prevalence calculations and statistical analyses. When recruited, most of the herd owners $(\mathrm{n}=87)$ were asked if they perceived UCD as a problem in their herd. Of these, $83 \%(\mathrm{n}=$ 72) did not, as they thought they had no or very few affected cows.

\section{UCD Prevalence}

The overall prevalence of UCD was $28 \%(969 / 3,479$ cows; 95\% CI: 26-29\%) and the proportion of cows with mild and severe UCD was 19\% (653/3,479 cows; 95\% CI: $18-20 \%$ ) and 9\% (316 of 3,479 cows; 95\% CI: 8-10\%), respectively. The overall within-herd prevalence ranged from 0 to $62 \%$ (mean $28 \%$, SD $15 \%$ ); it varied between 0 and $43 \%$ (mean 19\%, SD 10\%) for mild UCD, and between 0 and $33 \%$ (mean 9\%, SD 8\%) for severe UCD (Figure 1). One herd had no UCD, 15 herds had only mild cases, and 3 herds had only severe cases of UCD.

\section{Risk Factors Associated with Mild UCD}

In total, 3,163 cows from 99 herds were included in the univariable analyses for mild UCD. Of 85 variables, 31 had $P$-values $\leq 0.20$ and were kept for further analyses in 1 of the 4 multivariable sub-models (Supplemen- tal Tables S1 and S2; https://doi.org/10.3168/jds.2017 -13133). Eleven variables were tested in the sub-model for cow-related factors, 6 in the general herd and housing sub-model, 4 in the management sub-model, and 10 in the herd health sub-model. All variables associated $(P \leq 0.05)$ with mild UCD (Table 2$)$ were entered into the final model. This final model initially included 11 variables, of which 5 remained significant. When retesting variables with $P \leq 0.20$ in the univariable analyses, the herd incidence rate of culling due to hoof and leg diseases was significant and therefore included in the final model. As some cows were missing data for one or more variables, the number of cows in the final model was 2,821 from 97 herds.

The final multivariable mixed-effect logistic regression model is presented in Table 3. Breed, fore udder attachment, and HL were cow-related variables significantly associated with the outcome. Swedish Red cows had a higher probability of mild UCD than SH cows $(P$ $<0.001)$ or $\mathrm{SH} \times \mathrm{SR}$ cows $(P=0.04)$, and the $\mathrm{SH} \times$ SR cows had a higher risk than SH cows. Cows with HL had a greater risk of mild UCD than cows with no HL. Cows with intermediate fore udder attachment also had a greater risk than cows with strong fore udder attachment. The risk for mild UCD did not differ for loose fore udder attachments and the other categories. In addition, the analyses identified an interaction between parity and I/F. Cows with I/F had a higher risk of mild UCD than cows without I/F, but the linear increase in risk with increasing parity in cows without $\mathrm{I} / \mathrm{F}$ was not seen in cows with I/F (Figure 2). For both groups (cows with and without I/F), the risk of UCD

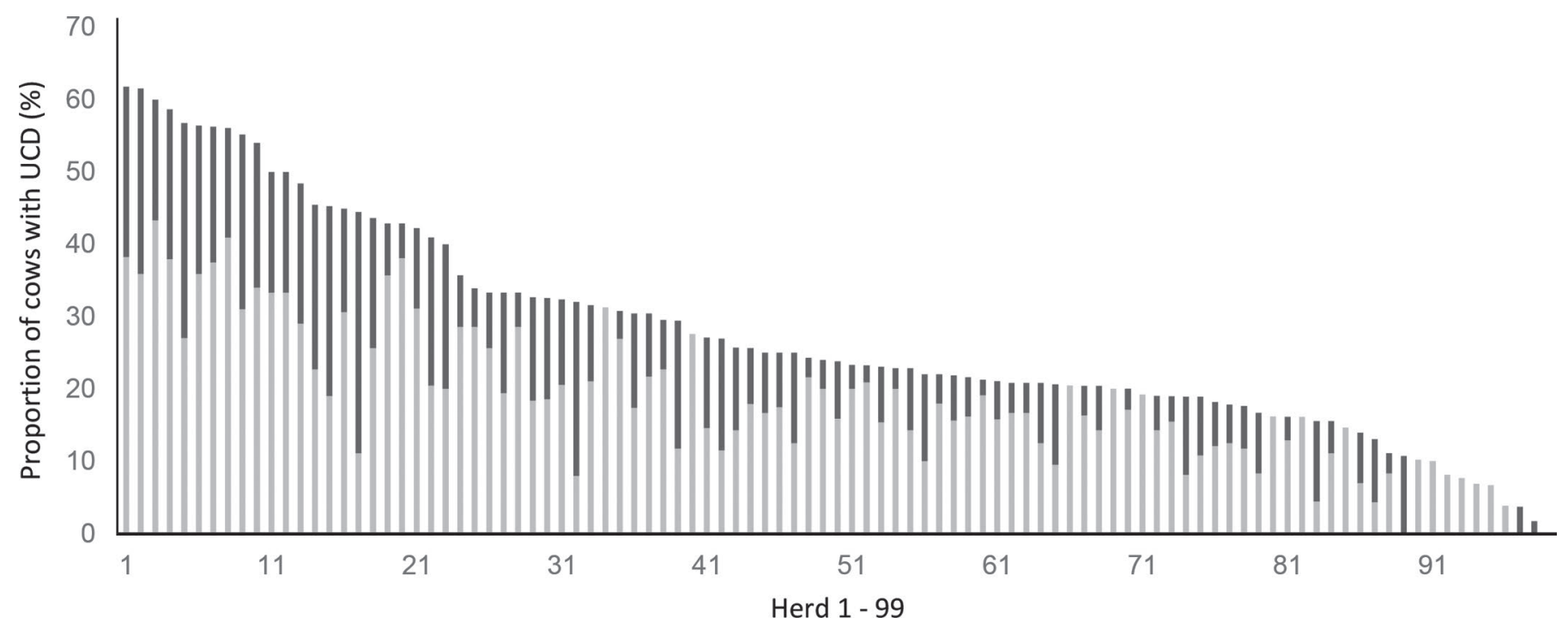

Figure 1. Within-herd prevalence (\%) of mild (light gray) and severe (dark gray) udder cleft dermatitis (UCD) in 3,479 dairy cows in 99 Swedish freestall dairy herds. Each bar on the x-axis represents 1 herd. 
was significantly higher for cows in higher parities than for first-parity cows $(P \leq 0.01)$. Only one herd-related variable was significantly associated with mild UCD in the final model - cows in herds with a high proportion of culling due to hoof and leg diseases had a higher risk than cows in herds with low proportion of culling. The random effect of cows within herd was significant in the final model $(P<0.001)$. The model showed good fit to the data, and the assumptions of normality and equal variance were verified in the residual plots.

Table 2. Cow- and herd-related variables significantly associated $(P \leq 0.05)$ with mild udder cleft dermatitis (UCD) in four multivariable, mixed-effect, logistic regression sub-models

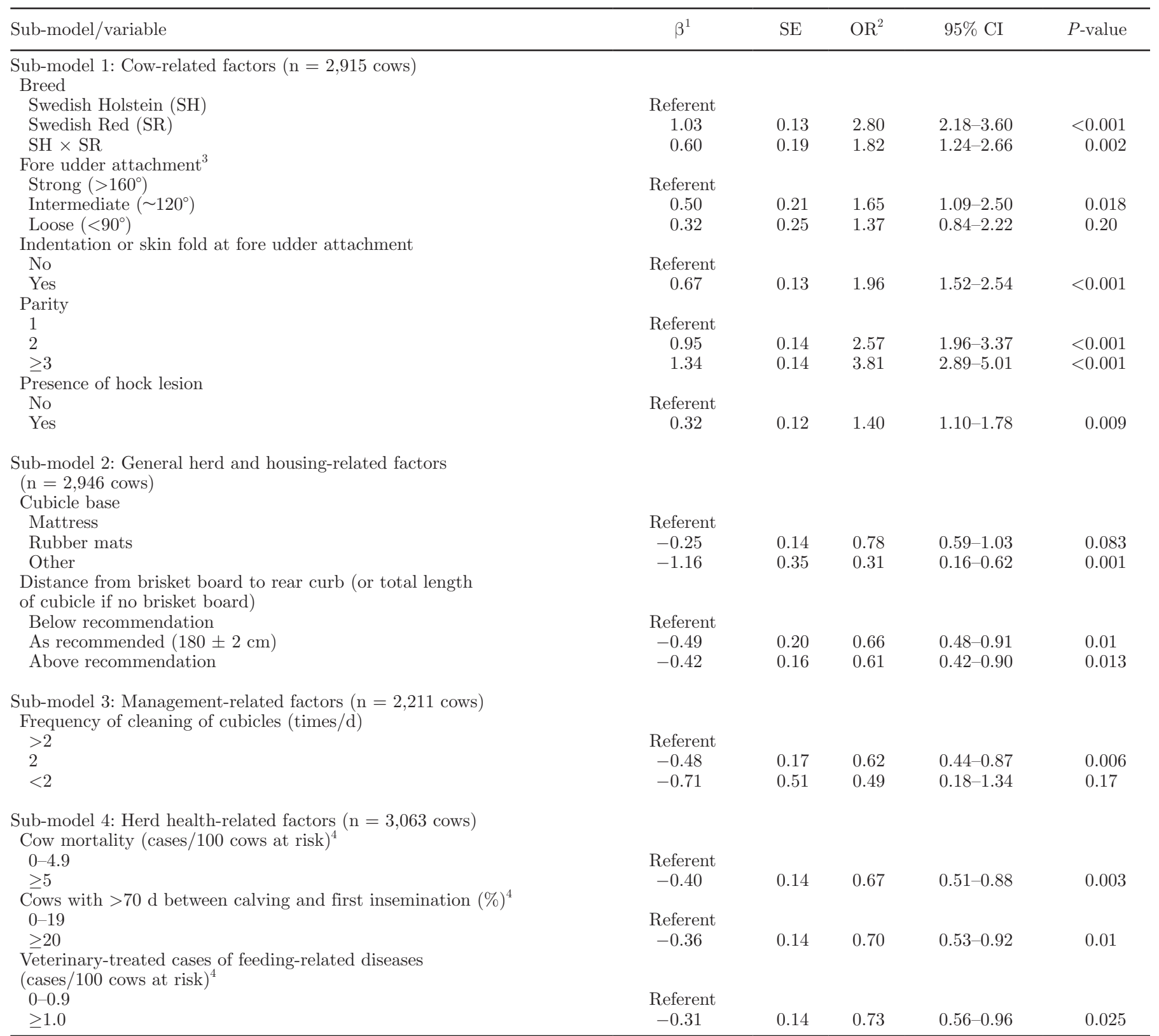

${ }^{1} \beta=$ regression coefficient.

${ }^{2} \mathrm{OR}=$ odds ratio.

${ }^{3}$ Ocular evaluation of the angle at the anterior udder attachment, between udder and abdominal wall (strong: $>160^{\circ}$, intermediate: $\sim 120^{\circ}$, or loose: $\left.<90^{\circ}\right)$.

${ }^{4}$ Herd incidence rate or proportion based on data from the Swedish Official Milk Recording Scheme (SOMRS) for the 12 mo preceding the herd visit. 


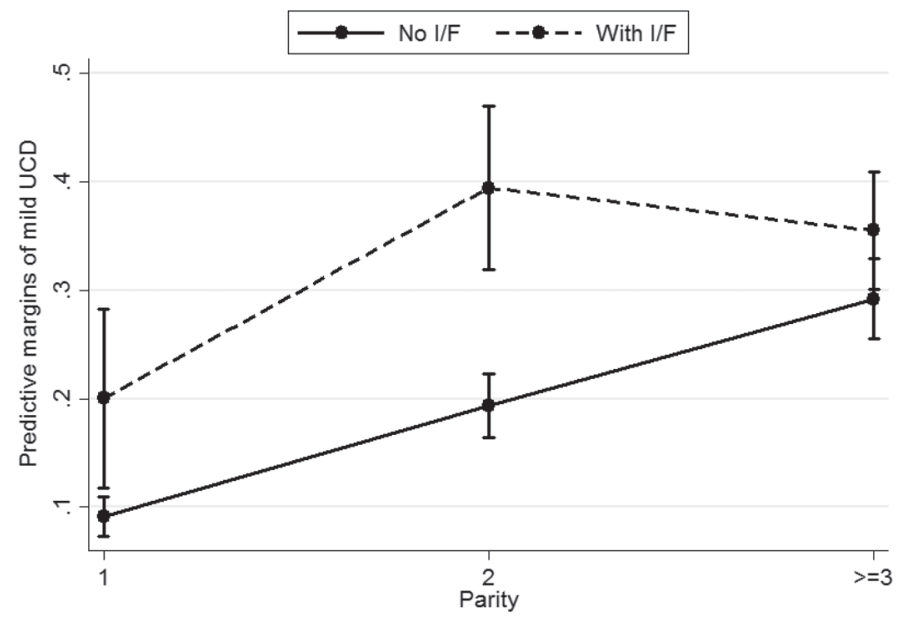

Figure 2. Associations between risk of mild udder cleft dermatitis (UCD), parity, and udder conformation [with or without indentation or skin fold (I/F) at the fore udder attachment]. First-parity cows and cows without I/F had generally a lower risk for mild UCD, but for cows without I/F there was a linear increase in risk with higher parity, whereas cows with $\mathrm{I} / \mathrm{F}$ in their second parity had as high risk as cows in their third or higher parity. Whiskers indicate $95 \% \mathrm{CI}$, based on a multivariable, mixed-effect, logistic regression model of 2,821 cows from 97 Swedish freestall dairy herds.

\section{Risk Factors Associated with Severe UCD}

The evaluation of risk factors for severe UCD included 2,826 cows from 99 herds in the univariable analyses. Of 85 variables analyzed, 37 had a $P$-value $\leq 0.20$ and were kept for further analyses in 1 of the 4 multivariable sub-models. In total, 14 variables were tested in the model for cow-related factors (including DIM as a confounder to milk yield), 8 in the model for herd and housing-related factors, 5 in the model for management-related factors, and 11 in the model for herd health-related factors (Supplemental Tables S1 and S2; https://doi.org/10.3168/jds.2017-13133). All variables significantly associated $(P \leq 0.05)$ with severe UCD in the sub-models are presented in Table 4 . These were then entered into the final model that initially contained 16 explanatory variables. When retesting variables that had a result of $P \leq 0.20$ in the univariable analyses, distance from brisket board to rear curb (or total length of cubicle if no brisket board) and herd incidence rate of VTCM (cases/100 cows at risk) were significant and therefore kept in the final model.

The final multivariable logistic regression model for risk factors associated with severe UCD included

Table 3. Results of the final multivariable mixed-effect logistic regression analysis for cow- and herd-related factors associated with mild udder cleft dermatitis (UCD) in 2,821 cows in 97 Swedish dairy herds

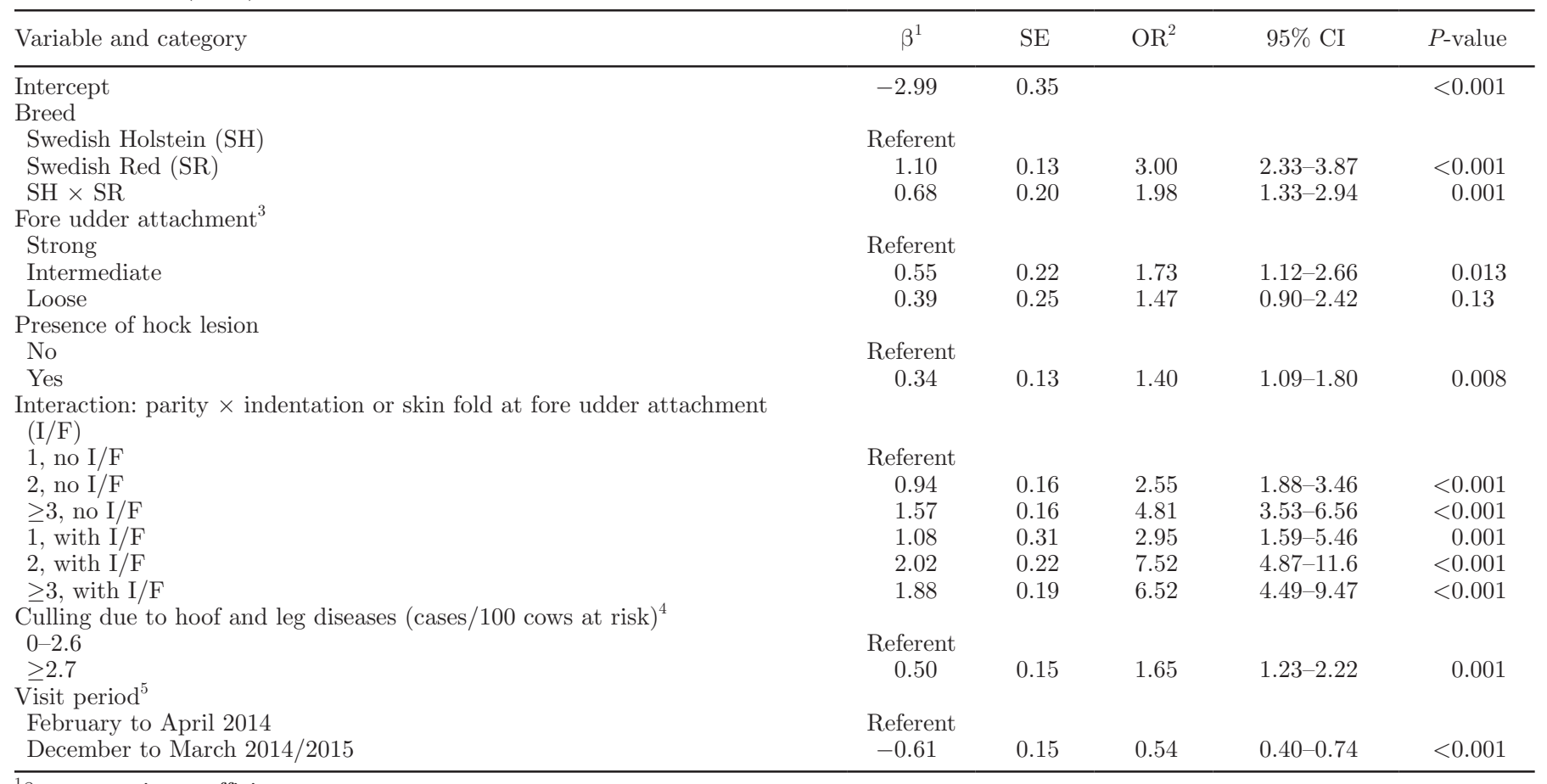

${ }^{1} \beta=$ regression coefficient.

${ }^{2} \mathrm{OR}=$ odds ratio.

${ }^{3}$ Ocular evaluation of the angle at the anterior udder attachment, between udder and abdominal wall (strong: $>160^{\circ}$, intermediate: $\sim 120^{\circ}$, or loose: $\left.<90^{\circ}\right)$.

${ }^{4}$ Herd incidence rate based on data from the Swedish Official Milk Recording Scheme.

${ }^{5}$ Included as a confounder. 
2,489 cows from 90 herds (Table 5). The risk factors included DIM, milk yield, and parity, with a higher risk of severe UCD for cows with higher DIM and high milk yield and a linear increase in risk with increasing parity. An interaction was seen between breed and fore udder attachment. Cows of the SH breed had lower risk of severe UCD than cows of the $\mathrm{SR}$ and $\mathrm{SH} \times \mathrm{SR}$ breeds $(P<0.001)$. Moreover, there was a lower risk of severe UCD for cows of the SH breed with a strong fore udder attachment, which was not seen for cows of the SR breed - the SR cows had slightly lower risk of severe UCD $(P=0.02)$ if they had a loose fore udder attachment compared with an intermediate attachment (Figure 3). For SH $\times$ SR cows, fore udder attachment did not affect the risk of severe UCD.

Three herd performance indicators were associated with severe UCD. These were the incidence rate of VTCM, culling of first-parity cows in early $(0-90 \mathrm{~d})$ lactation, and culling due to udder diseases, based on SOMRS data from the 12 mo preceding the visit. The risk for severe UCD was lower for cows in herds with 3.32 to 10.0 cases of VTCM than for cows in herds with other incidence rates of VTCM. The risk for severe UCD did not differ significantly between the other categories of herd incidence of VTCM. A higher risk for severe UCD was seen among cows in herds with a low incidence of culled first-parity cows in early lactation. Cows in herds with a high incidence rate of culling due to udder diseases had a higher risk of severe UCD than cows in herds with a low proportion of such culling.

Other herd-related factors associated with severe UCD included distance from brisket board to rear curb, cubicle base, and installation year of the cubicles. A distance greater than recommended from brisket positioner to the rear curb of the cubicle was associated with a lower risk for severe UCD than if the distance was as recommended or below recommendation. If cubicles did not have a brisket positioner, the total length of the lying area was measured; these cubicles were mostly in the "greater than recommended" category. The risk of severe UCD did not differ significantly between cubicles with the recommended and below-recommended distances. Cows in herds with a mattress as cubicle base had a higher risk for severe UCD than cows in herds with rubber mats or other cubicle base (e.g., concrete or deep-straw bedding). Cows in herds where cubicles were installed between 2001 and 2005 had a lower risk for severe UCD than cows in herds where cubicles were installed in 2000 or earlier. The risk of severe UCD did not differ significantly between cubicles installed after 2005 and the other 2 categories. The random effect of herd was not significant $(P=0.19)$ and was therefore removed from the analysis. The model explained about $21 \%$ of the variation in the data $\left(\mathrm{R}^{2}=0.21\right)$. The model fit was good, and the assumptions of normality and equal variance were verified in the residual plots.

\section{Risk Factors Associated with All UCD}

The evaluation of risk factors for all UCD included 3,479 cows from 99 herds in the univariable analyses. Of 85 variables analyzed, 36 had a $P$-value $\leq 0.20$ and were kept for further analyses in 1 of the 4 multivariable sub-models. In total, 13 variables were tested in the model for cow-level factors, 6 in the model for herd and housing-related factors, 5 in the model for management-related factors, and 12 in the model for herd health-related factors (Supplemental Tables S1 and S2; https://doi.org/10.3168/jds.2017-13133). All variables significantly associated $(P \leq 0.05)$ with all UCD in the sub-models are presented in (Supplemental Table S3; https://doi.org/10.3168/jds.2017-13133). These were then entered into the final model that initially contained 10 explanatory variables. When retesting variables that had a result of $P \leq 0.20$ in the univariable analyses, herd incidence rate of VTCM (cases/100 cows at risk) was significant, as was the percentage of heifers not inseminated at $>17$ mo of age, and these were therefore kept in the final model.

The final multivariable logistic regression model for risk factors associated with all UCD included 3,215 cows from 93 herds (Supplemental Table S4; https:// doi.org/10.3168/jds.2017-13133). The risk factors included breed in an interaction with fore udder attachment, as well as parity in an interaction with $\mathrm{I} / \mathrm{F}$. Cows of the SH breed had lower risk of UCD than cows of the SR and SH $\times$ SR breeds $(P \leq 0.002)$, except for cows with a strong udder attachment where there were no differences between cows of $\mathrm{SH}$ and $\mathrm{SH} \times \mathrm{SR}$ breeds $(P$ $=0.14$ ). Moreover, there was a lower risk of UCD for $\mathrm{SH}$ cows with a strong fore udder attachment compared with an intermediate or loose attachment $(P \leq 0.006)$, which was not seen for SR cows. Instead, SR cows had a lower risk of UCD if they had a loose fore udder attachment compared with an intermediate attachment $(P=$ 0.009). For $\mathrm{SH} \times \mathrm{SR}$ cows, fore udder attachment did not affect the risk of UCD. For the interaction between parity and I/F, the results showed that cows with $\mathrm{I} / \mathrm{F}$ had a higher risk of UCD than cows without I/F $(P<$ $0.001)$ except for cows in parity 3 or higher $(P=0.21)$. A linear increase in UCD with increasing parity was seen for cows without I/F but not for cows with I/F. For both groups (cows with and without I/F), the risk of UCD was higher for cows in higher parities than in first-parity cows $(P \leq 0.007)$.

Two herd performance indicators were associated with UCD. These were the incidence rate of VTCM and proportion of heifers not inseminated at $>17$ mo of 
Table 4. Cow- and herd-related variables significantly associated $(P \leq 0.05)$ with severe udder cleft dermatitis (UCD) in four multivariable, mixed-effect, logistic regression sub-models

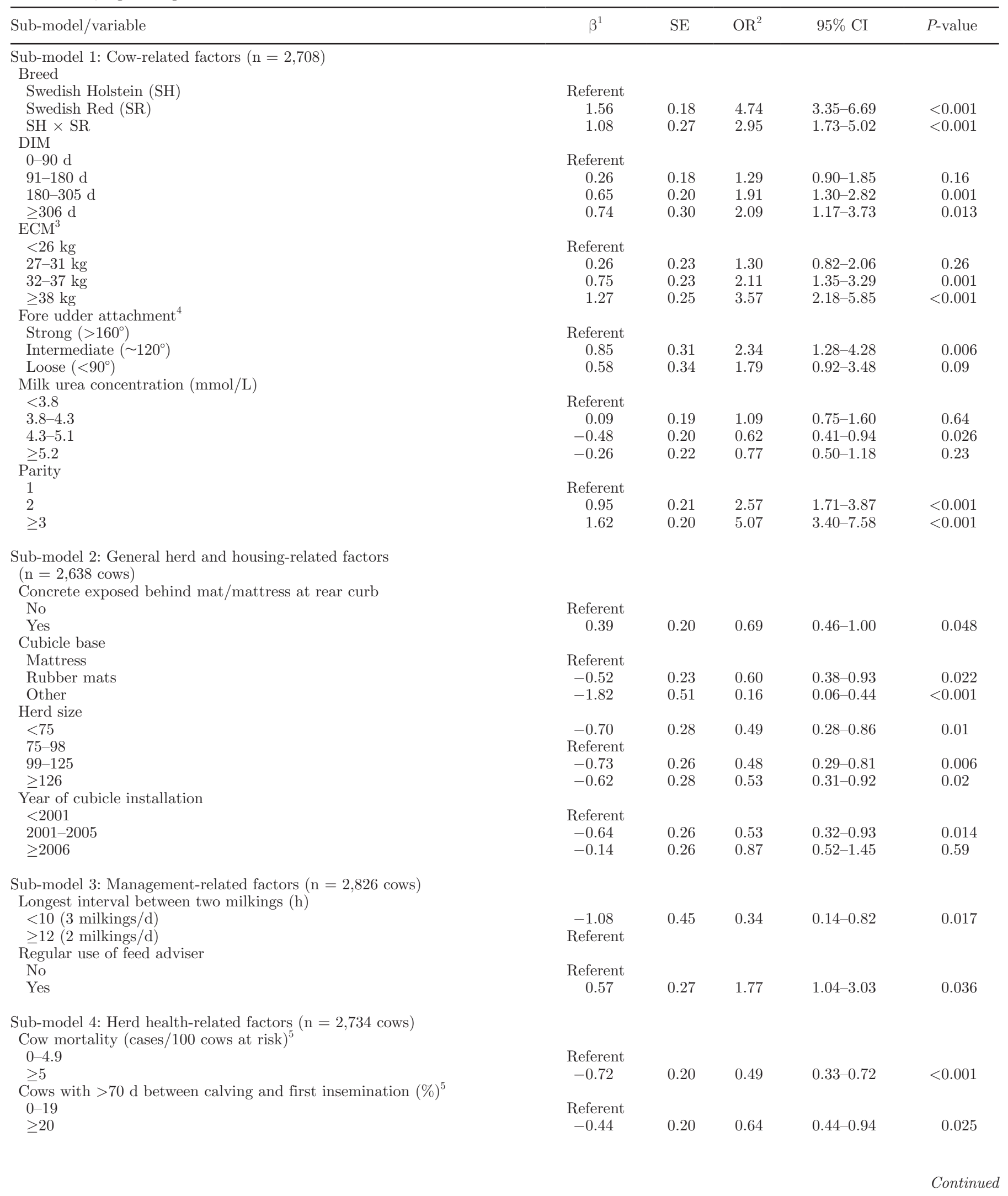


Table 4 (Continued). Cow- and herd-related variables significantly associated $(P \leq 0.05)$ with severe udder cleft dermatitis (UCD) in four multivariable, mixed-effect, logistic regression sub-models

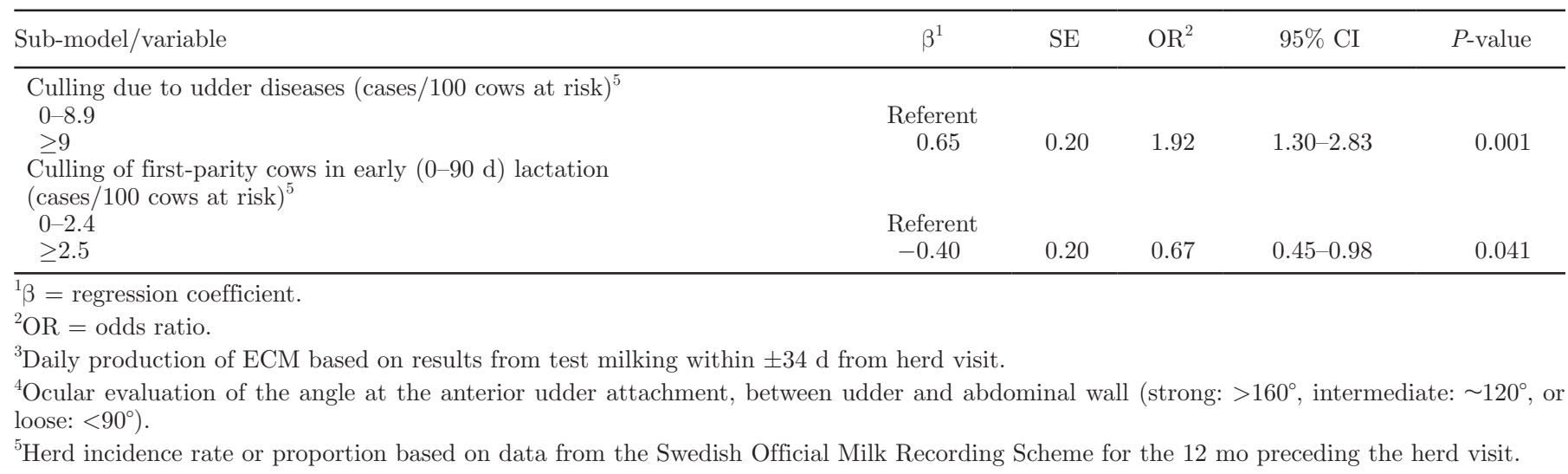

age, based on SOMRS data from the 12 mo preceding the visit. The risk for UCD was lower for cows in herds with 3.32 to 9.99 cases of VTCM than for cows in herds with 0.0 to 3.31 cases of VTCM or herds with 10.0 to 15.71 cases. The risk for UCD was also lower in herds with $\geq 15.72$ cases than in herds with 10.0 to 15.71 cases $(P=0.044)$. Cows in herds with $\geq 17 \%$ of heifers not inseminated at $>17$ mo of age had a lower risk of UCD than cows in herds with 0 to $16 \%$ of heifers not inseminated at $>17$ mo of age.

Another herd-level factor associated with all UCD was cubicle base. Cows in herds with mattresses had a higher risk for UCD than cows in herds with rubber mats or other cubicle base (e.g., concrete or deep-straw bedding). The random effect of cows within herd was significant in the final model $(P<0.001)$. The model fit was good, and the assumptions of normality and equal variance were verified in the residual plots.

\section{Associations Between UCD and Mastitis and Culling}

The analysis of associations between mild UCD and VTCM or culling included 3,063 cows from 97 herds. For milk SCC, only 3,033 cows were included because of missing data in the SOMRS. In the univariable mixedeffect linear regression analysis, cows with mild UCD had a higher milk SCC than cows without UCD $(P<$ $0.001)$, but the association was no longer significant $(P$ $=0.58$ ) when parity was included as a confounding factor. The other potential confounders (breed, DIM, and milk yield) had no confounding effect on mild UCD, although DIM and milk yield were significantly associated with SCC. There was no significant association between mild UCD and VTCM within $90 \mathrm{~d}$ before or after the visit.

In the analyses of associations between severe UCD and VTCM or culling, 2,734 from 97 herds were in- cluded and 2,708 for milk SCC. As for the univariable analysis of mild UCD, cows with severe UCD had a higher SCC than cows without UCD $(P=0.012)$, but this association was no longer significant when parity was included as a confounder $(P=0.48)$. The other potential confounders had no confounding effect on severe UCD, although all of them were significantly associated with SCC. Severe UCD was associated with a higher risk of VTCM $(P=0.005)$ in the univariable analysis, but the association was no longer significant when parity was included as confounder $(P=0.14)$.

The analysis of associations between all UCD and VTCM or culling included 3,372 cows from 97 herds. For milk SCC, only 3,339 cows were included because of missing data in the SOMRS. In the univariable mixed-effect linear regression analysis, cows with UCD had a higher SCC than cows without UCD $(P<0.001)$, but the association was no longer significant when parity was included as a confounding factor $(P=0.87)$. The other potential confounders (breed, DIM, and milk yield) had no confounding effect on UCD, although they were significantly associated with SCC. We also detected a significant association between VTCM within $90 \mathrm{~d}$ before or after the visit and UCD in the univariable analysis; cows with UCD had a higher risk of being VTCM within $90 \mathrm{~d}$ before or after the visit $(P=0.05)$. However, the association was no longer significant $(P$ $=0.82$ ) when parity was included as a confounding factor. The other potential confounders (breed, DIM, and milk yield) had no confounding effect on UCD, although DIM was significantly associated with SCC.

In total, $7 \%$ (245 of 3,479) of the cows were culled within $90 \mathrm{~d}$ after the visit. The most common registered reasons were udder health problems (72 cows) or decreased fertility (58 cows). A higher risk of culling (for any reason) within $90 \mathrm{~d}$ after the visit was seen in the univariable analysis $(P=0.002)$ for cows with mild 
Table 5. Results of the final multivariable, logistic regression analysis for cow- and herd-related factors associated with severe udder cleft dermatitis (UCD) in 2,489 cows in 90 dairy herds

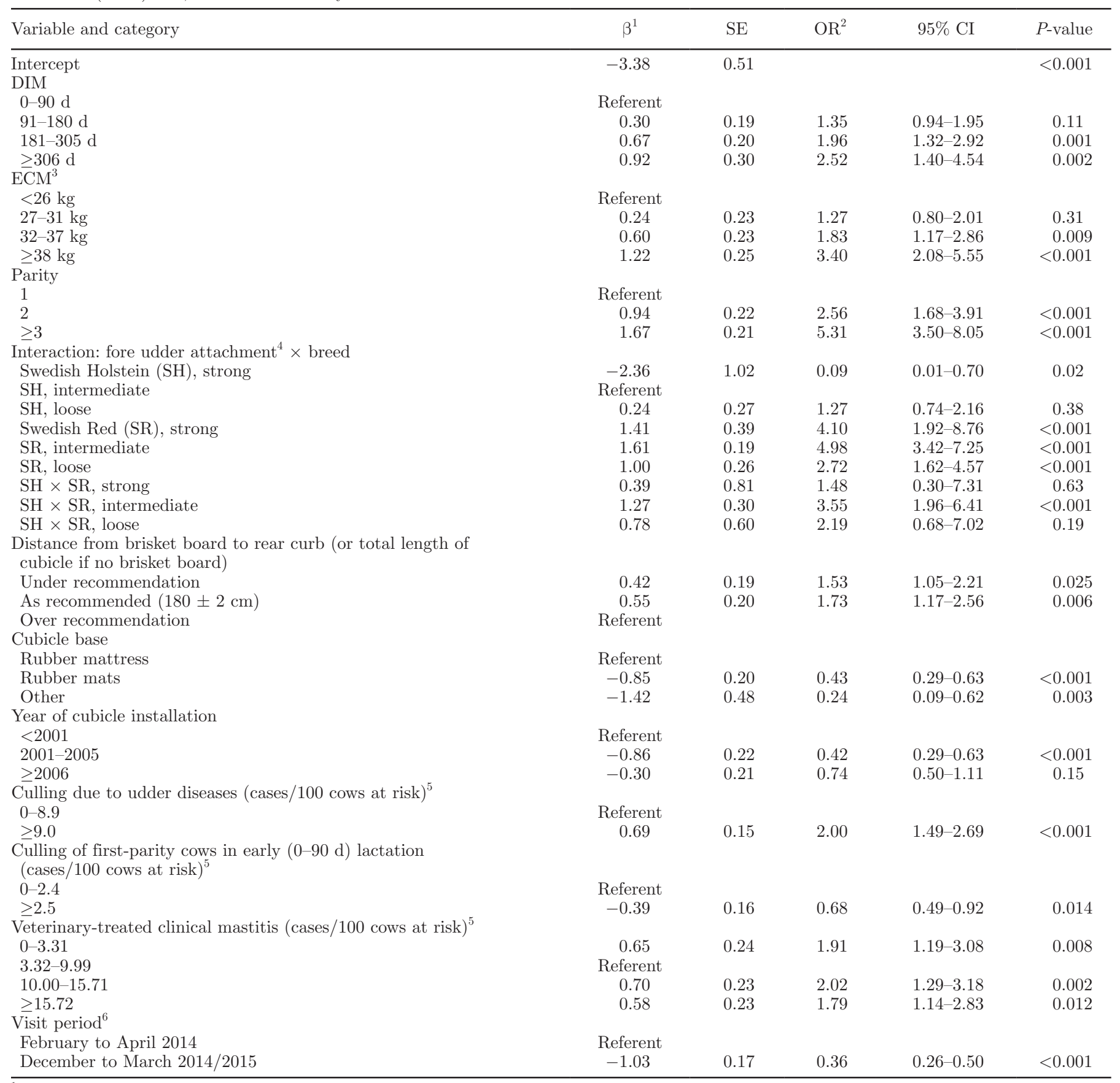

${ }^{1} \beta=$ regression coefficient.

${ }^{2} \mathrm{OR}=$ odds ratio.

${ }^{3}$ Daily production of ECM based on results from test milking within $\pm 34 \mathrm{~d}$ from herd visit.

${ }^{4}$ Ocular evaluation of the angle between udder and abdominal wall (strong: $>160^{\circ}$, intermediate: $\sim 120^{\circ}$, or loose: $<90^{\circ}$ ).

${ }^{5}$ Herd incidence rate based on data from the Swedish Official Milk Recording Scheme for the 12 mo preceding the herd visit.

${ }^{6}$ Included as a confounder. 


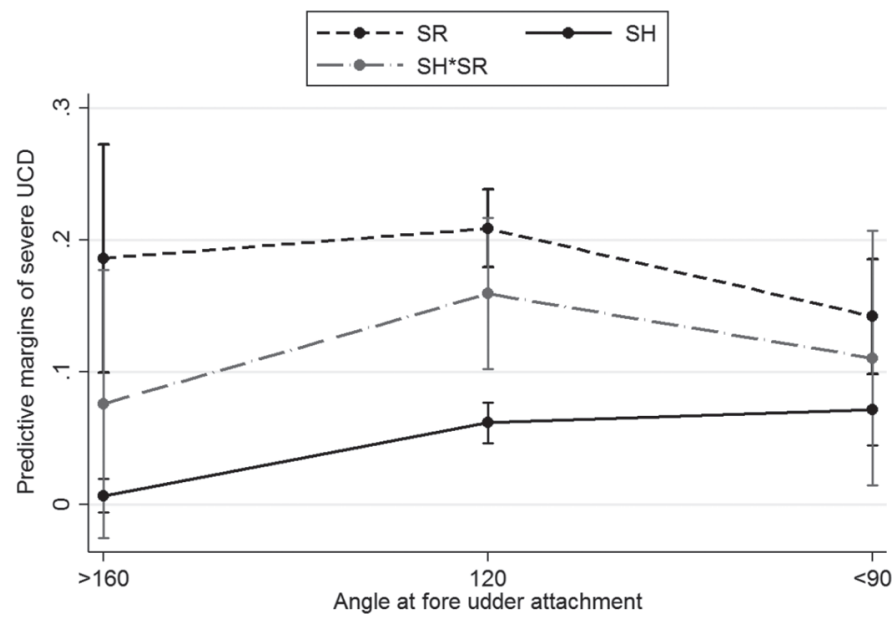

Figure 3. Associations between risk of severe udder cleft dermatitis (UCD), breed (Swedish Holstein, SH; Swedish Red, SR; or cross-breed, $\mathrm{SH} \times \mathrm{SR}$ ), and fore udder attachment. The SH cows had a lower risk of severe UCD if they had a strong fore udder attachment, whereas SR cows with a loose fore udder attachment had lower risk than SR cows with intermediate fore udder attachment. The angle of the anterior udder attachment between udder and abdominal wall was determined visually as strong $>160^{\circ}$, intermediate $\sim 120^{\circ}$, or loose $<90^{\circ}$. Whiskers show the $95 \%$ CI, based on the results of a multivariable logistic regression model of 2,489 cows in 90 Swedish freestall dairy herds.

UCD and all UCD, but not when parity was included as a confounder $(P=0.11$ and $P=0.33$, respectively). There was no significant association between severe UCD and culling.

\section{DISCUSSION}

To the best of our knowledge, this is the largest and most comprehensive study performed on the prevalence of, and risk factors for, UCD in dairy cows. This is also the first study to model risk factors separately for mild and severe UCD. The results emphasize the importance of preventing UCD because it is a common condition in dairy cows, and important risk factors have been identified.

\section{Prevalence of UCD in Cows and Herds}

We found the total prevalence of UCD in dairy cows to be considerably higher (28\%) than in a previous study that used an almost identical scoring system in 30 randomly selected herds in one Swedish county (18\%; Persson Waller et al., 2014). One reason for the difference could be that UCD is increasing but there may also have been differences in scoring between individual observers or in the selection criteria of herds. The prevalence was also much higher than in a Dutch study in 20 randomly selected herds (Olde Riekerink et al., 2014). However, that study used a different scoring system, making it difficult to compare results. Moreover, the Dutch dairy population consists mainly of Holstein-Friesian cows. The distribution of mild and severe cases of UCD in our study, indicating that approximately one-third of UCD cows had severe lesions, was in line with previous results (Persson Waller et al., 2014). The fact that $9 \%$ of the cows had severe UCD lesions and that severe lesions were found in 83 of 99 herds indicates that UCD is a rather common animal welfare problem in Swedish dairy herds.

Although UCD lesions were found in almost all herds, there was large variation in the total within-herd prevalence of UCD and its degree (mild or severe). This is in line with previous studies (Olde Riekerink et al., 2014; Persson Waller et al., 2014), indicating that herd factors are important for both prevalence and severity of the lesions.

\section{Cow Factors Associated with UCD}

Several cow risk factors were common to both mild and severe UCD, whereas other factors were associated with only mild or only severe lesions. The risk factors identified in the models for all UCD were also found for mild or severe UCD, or for both types, but more risk factors were identified for mild or severe UCD than for all UCD. Below, the results are discussed for mild and severe UCD with comments on findings for all UCD when appropriate.

Cow Factors Associated with Both Mild and Severe $U C D$. Factors significant for both mild and severe UCD, as well as all UCD, were breed, udder conformation, and parity. Independent of severity, SR cows had a greater risk of UCD than SH cows, as reported previously by Persson Waller et al. (2014). Why this should be so is unclear but differences in udder conformation may be relevant. A strong fore udder attachment was associated with a lower risk for mild UCD in all cows and for severe UCD in SH cows. Previous studies have reported a lower risk for UCD lesions in cows with a strong fore udder attachment (Persson Waller et al., 2014) and an increased risk of UCD for cows with a loose fore udder attachment (Hansen and Nissen, 2010; Olde Riekerink et al., 2014). In contrast, the risk for severe UCD in SR cows was slightly lower for cows with a loose fore udder attachment than for those with an intermediate attachment. The reason for this is unknown but emphasizes that udder conformation is an important factor for UCD. The SH cows had better scores for several udder conformation traits in the breeding evaluation because SH cows tend to have less deep udders and a stronger udder support compared 
with SR cows (Växa Sverige, 2008). As these traits are difficult to score objectively in the milking parlor, we did not investigate them in our study. Therefore, they could have been "hidden" in the breed variable and affected the association between breed and UCD. A significant association between increased udder depth and increased risk of UCD was indeed found by Hansen and Nissen (2010) and Olde Riekerink et al. (2014), but a strong median suspensory ligament (udder support) had no association (Olde Riekerink et al., 2014) or was associated with a higher risk of UCD (Hansen and Nissen, 2010) in other studies.

The risk for UCD increased with parity, in agreement with other studies (Warnick et al., 2002; Persson Waller et al., 2014; Bouma et al., 2016). It might be speculated that older cows per se are more susceptible to UCD, as with several other diseases, including mastitis and HL (Kester et al., 2014; Växa Sverige, 2017), but the increased risk could also be due to changes in udder conformation over time. In addition, the chronic nature of UCD (Bouma et al., 2016) may explain its higher prevalence in older cows.

Cow Factors Associated with Only Mild UCD. In addition to factors mentioned above, I/F and HL were significantly associated with an increased risk of mild UCD, and I/F was also significant in the model for all UCD. This is in agreement with a previous study that found a tendency for increased risk for UCD for cows with an $\mathrm{I} / \mathrm{F}$ at the fore udder (Persson Waller et al., 2014). As discussed by others (Beattie and Taylor, 2000; Hansen and Nissen, 2010), UCD lesions are similar to intertrigo or skin fold dermatitis in other species. Skin folds resulting in a moist and enclosed environment are harmful to the skin barrier and predispose it to secondary microbiological infection (Hansen and Nissen, 2010; Foster, 2012). The increased risk of mild UCD in cows with HL might be due, at least partly, to risk factors common to both HL and UCD, such as parity (Kester et al., 2014). However, SH cows generally have more HL than other breeds, including SR cows (Kester et al., 2014; Gustafsson et al., 2016), whereas the opposite is the case for mild UCD. The association between HL and mild UCD requires further investigation, but it could be speculated that some cows are more predisposed to skin lesions than others or that certain herd or management factors contribute to an increased prevalence of both UCD and HL.

Cow Factors Associated with Only Severe UCD. High milk yield and increasing DIM were significantly associated with increased risk of severe UCD, associations also reported in previous studies (Olde Riekerink et al., 2014; Persson Waller et al., 2014; Bouma et al., 2016). High milk yield could result in greater pressure within the udder, leading to reduced blood circulation (Blowey and Edmondson, 2010; Hansen and Nissen, 2010) and possibly local skin damage from tissue necrosis. In the univariable analysis and in the sub-model for management factors, the risk for severe UCD was significantly lower for cows milked thrice daily than for those milked twice, a finding that supports the role of pressure in the udder as a contributing factor to UCD. The higher risk of severe UCD in cows later in lactation could be related to changes in udder conformation over the lactation period (Gustafsson, 1998), resulting in more skin folds in the affected area. Moreover, a lesion that develops early in lactation is likely to persist, thereby contributing to the increased prevalence later in lactation (Bouma et al., 2016).

\section{Herd Factors Associated with Mild and Severe UCD}

Interestingly, no herd-related risk factors were common to mild and severe UCD, but some risk factors were associated with either mild or severe lesions. Some, but not all, of those herd-related risk factors were also found for all UCD. In addition, a low herd proportion of heifers older than 17 mo and not inseminated was a risk factor for all UCD. The reasons for this finding are unknown. The random effect of herd was significant in all models except the final model for severe UCD, which indicates that the main effects included in the initial models do not explain all the variation in UCD prevalence. Moreover, the final model for severe UCD explained only about $21 \%$ of the variation in the data set. Thus, additional herd factors must affect UCD occurrence that were not revealed by the study. Below, the results are discussed for mild and severe UCD, with comments on findings for all UCD when appropriate.

Herd Factors Associated with Only Mild UCD. Only 1 of the 67 herd-related variables was significantly associated with mild UCD, implying that cow-related factors are more important for the outcome. The increased risk of mild UCD for cows in herds with a high proportion of cows culled for hoof and leg diseases needs further investigation. It may be related to the association between mild UCD and HL, as the association between HL and lameness is well established (Kester et al., 2014). Lame cows alter their behavior and lie down for longer periods than nonlame cows (Chapinal et al., 2010). This behavior could increase the risk of UCD as the udder becomes exposed to increased pressure and airtight skin folds when the cow is lying down.

Herd Factors Associated with Only Severe $\boldsymbol{U C D}$. In contrast to mild UCD, 3 housing-related factors and 2 herd-performance indicators related to udder health were significantly associated with severe 
UCD. Cows housed in freestalls with rubber mattresses had a higher risk of severe UCD than cows housed on rubber mats. The same was found for all UCD. We hypothesize that this could be due to a warmer and moister environment for the udder when the cows lie on mattresses, which are usually thicker and softer than mats. Moreover, in several herds, the mattress filling had been compressed, resulting in indentations where urine and manure could accumulate (data not shown), which could be harmful to the skin barrier. A longer distance between brisket board and rear curb was associated with a lower probability of severe UCD. This could be because a longer distance gives the cow more room to position and extend her body, resulting in fewer skin folds and more air circulation around the front of the udder. The reasons behind the lower risk of severe UCD in cows housed in cubicles installed between 2001 and 2005 are not known. It is possible that freestalls installed during this period share some attribute that influences UCD prevalence, but the finding could also be due to a type I error. There was no difference between cubicles installed before 2001 or after 2005, so cubicle age per se cannot account for the lower risk in the cubicles installed between 2001 and 2005. No previous study has investigated associations between UCD and these housing-related factors, so further investigations are warranted.

There was a higher risk of severe UCD for cows in herds with high rates of VTCM and of culling due to udder diseases. The association with VTCM was also found for all UCD. The findings might indicate an association between severe UCD and udder health, but it could also be due to some unidentified management factors affecting the rate of VTCM and culling as well as severe UCD. Persson Waller et al. (2014) found no association between herd incidence of VTCM and UCD but did find an increased risk for UCD in cows with registered VTCM within $30 \mathrm{~d}$ of the UCD observation. The reasons for the higher risk for severe UCD among cows in herds with a low incidence of culled first-parity cows in early lactation are not known.

\section{Associations Between UCD and Udder Health and Culling}

Clearly, factors that affect the overall health and immune status of the cow might also affect the occurrence of UCD. We hypothesized that UCD lesions might increase the risk of udder health problems and premature culling. The univariable analyses showed that both mild and severe UCD, as well as all UCD, were significantly associated with increased SCC, and cows with severe or all types of UCD had an increased risk for VTCM within $90 \mathrm{~d}$ after the herd visit. However, when including the confounding factor of parity in the models, the effects of UCD were no longer significant. Other studies have found no associations between UCD and SCC on either the cow level (Persson Waller et al., 2014) or the herd level (Olde Riekerink et al., 2014; Persson Waller et al., 2014). However, the associations between UCD and VTCM (Persson Waller et al., 2014) and between UCD and herd performance indicators related to udder health indicate the need to further investigate associations between UCD and udder health problems. Diseases are underreported to the SOMRS (Wolff et al., 2012), which means that the incidence of VTCM registered in the present study might not be completely reliable. To better understand the associations between UCD and udder health, a longitudinal study should investigate development of UCD lesions, changes in SCC, and the incidence rate of clinical mastitis.

The univariable analysis showed that mild and all UCD, but not severe UCD, were significantly associated with a higher risk of culling within $90 \mathrm{~d}$ after the herd visit. However, when parity was included in the model, the association was no longer significant. To our knowledge, the association between UCD and culling has not been investigated previously. Our results imply that factors other than UCD are more important for the risk of culling.

\section{Additional Comments}

The study - designed to investigate several possible cow- and herd-related risk factors in a large number of herds - found previously unidentified risk factors. A cross-sectional study, however, only yields a snapshot of the conditions in the dairy herd. We cannot determine the duration of UCD or draw any conclusions about causality. Moreover, the large number of investigated explanatory variables increases the risk of type I errors; that is, identification of risk factors that are not true risk factors. In addition, the selection and categorization of the risk factors may have affected the results of the study. We plan to perform longitudinal studies on the development of different stages of UCD in a smaller number of herds to identify risk factors associated with the early phases of mild and severe UCD.

Our results imply that mild UCD is mainly associated with the type of udder conformation and the presence of other skin conditions, such as HL, whereas environmental factors contribute more to an increased risk for severe UCD. The involvement of microorganisms, such as treponemes and ectoparasites, has been suggested (Allenstein, 1991; Boyer and Singleton, 1998; Stamm et al., 2009), but other studies (Warnick et al., 
2002; Hansen and Nissen, 2010), including our own, give no such indications. However, due to the wide variation in within-herd prevalence of UCD and the fact that identified risk factors cannot fully explain the epidemiology of UCD, a role of infectious agents cannot be ruled out. Treponemes have been found in HL in dairy cows (Clegg et al., 2016) and in skin conditions in other species, such as porcine shoulder ulcers (Karlsson et al., 2014). They are highly invasive pathogens and could increase the severity of UCD lesions even if they are not the primary cause. Other studies have identified a variety of bacteria in severe UCD lesions (Beattie and Taylor, 2000; Warnick et al., 2002; Persson Waller, 2003). This type of lesion will inevitably contain many environmental and opportunistic bacteria; however, it is difficult to determine their role in development of the lesions. To our knowledge, no studies have compared the skin flora of healthy skin with that in different stages of UCD, or used non-culture-based methods such as next-generation sequencing to investigate the lesions. We plan to perform such studies to obtain more information on the etiology and pathogenesis of UCD.

\section{CONCLUSIONS}

Both mild and severe UCD lesions are common in Swedish dairy herds, which emphasizes the need for preventive measures and efficient treatments. Lesions were found in 98 of 99 herds, and within-herd prevalence ranged from 0 to $43 \%$ for mild UCD and from 0 to $33 \%$ for severe UCD. Several cow-related risk factors were common to both mild and severe UCD, such as parity and fore udder attachment, whereas other cow- and herd-related factors were associated with only mild lesions or only severe lesions. Severe UCD was associated with the herd incidence rates of VTCM and culling of cows due to udder health problems, but there were no associations between UCD and cow VTCM or SCC. The etiology of UCD is most likely multifactorial, involving udder conformation traits and other cow-related risk factors, as well as herd-related risk factors. An infectious cause or contributor to the condition cannot be ruled out, and studies investigating the microbiological flora of the lesions are warranted. Further longitudinal studies on UCD could yield more information on the etiology and pathogenesis of mild and severe lesions.

\section{ACKNOWLEDGMENTS}

This study was financially supported by The Swedish Research Council Formas (Stockholm) and The Swedish Farmers Foundation for Agricultural Research
(Stockholm). We also thank the farmers who were visited in the study for their helpful participation, and Maria "Maja" Persson (National Veterinary Institute, Uppsala, Sweden) for excellent technical assistance.

\section{REFERENCES}

Allenstein, L. C. 1991. Mites cause many of the smelly udder sores. Hoard's Dairyman 136:507.

Beattie, K. G., and D. J. Taylor. 2000. An investigation into intertrigo (necrotic dermatitis or 'foul udder') in dairy cows. Cattle Pract. 8:377-380.

Blowey, R. W.., and P. Edmondson. 2010. Structure of teats and udder and mechanisms of milk synthesis. Pages 5-10 in Mastitis Control in Dairy Herds. 2nd ed. CABI, Wallingford, UK.

Bouma, A., M. Nielen, E. van Soest, S. Sietsma, J. van den Broek, T. Dijkstra, and T. van Werven. 2016. Longitudinal study of udder cleft dermatitis in 5 Dutch dairy cattle herds. J. Dairy Sci. 99:4487-4495. https://doi.org/10.3168/jds.2015-9774.

Boyer, P., and G. Singleton. 1998. Digital dermatitis, superfoul and severe necrotic enteritis of the udder in dairy cows. Vet. Rec. 142:147-148.

Chapinal, N., A. M. de Passille, J. Rushen, and S. Wagner. 2010. Automated methods for detecting lameness and measuring analgesia in dairy cattle. J. Dairy Sci. 93:2007-2013. https://doi.org/10 $.3168 / \mathrm{jds} .2009-2803$.

Clegg, S. R., J. Bell, S. Ainsworth, R. W. Blowey, N. J. Bell, S. D. Carter, and N. J. Evans. 2016. Isolation of digital dermatitis treponemes from cattle hock skin lesions. Vet. Dermatol. 27:106-e30. https://doi.org/10.1111/vde.12286.

Cook, N. B., and D. J. Reinemann. 2007. A tool box for assessing cow, udder and teat hygiene. Pages 31-43 in Proc. 46th Annu. Mtg. Natl. Mastitis Counc., San Antonio, TX, Natl. Mastitis Counc., Madison, WI. Cornell University. Hock Assessment Chart for Cattle. Accessed May 5, 2017. https://ahdc.vet.cornell.edu/programs/ NYSCHAP/docs/HockScoringChart-NYSCHAP-4-04.pdf.

Dohoo, I., W. Martin, and H. Stryhn. 2010. Veterinary Epidemiologic Research. 2nd ed. VER Inc., Charlottestown, PEI, Canada.

Foster, A. P. 2012. Staphylococcal skin disease in livestock. Vet. Dermatol. 23:342-351. https://doi.org/10.1111/j.1365-3164.2012 .01093.x.

Gustafsson, Å. 1998. Genetiska studier av exteriöra juveregenskaper hos svenska mjölkkor. [Genetic studies of exterior udder traits of Swedish dairy cows]. MS thesis. Department of Animal Breeding and Genetics, Swedish University of Agricultural Sciences, Uppsala, Sweden.

Gustafsson, L., A. Nyman, E. Bagge, U. Magnusson, and K. Persson Waller. 2016. Prevalence and risk factors for hock lesions in Swedish dairy cows. Pages 293-294 in Proc. 29th Congr. World Buiatrics Assoc., Dublin, Ireland. Veterinary Ireland, Dublin, Ireland.

Hansen, M. J., and M. M. Nissen. 2010. A clinical study of udder cleft dermatitis on a Danish dairy farm. MS Thesis. Department of Large Animal Sciences, Faculty of Life Sciences, University of Copenhagen, Denmark.

Hosmer, D. W., and S. Lemeshow. 2000. Applied Logistic Regression. John Wiley \& Sons Inc., New York, NY.

Karlsson, F., K. Klitgaard, and T. K. Jensen. 2014. Identification of Treponema pedis as the predominant Treponema species in porcine skin ulcers by fluorescence in situ hybridization and highthroughput sequencing. Vet. Microbiol. 171:122-131. https://doi .org/10.1016/j.vetmic.2014.03.019.

Kester, E., M. Holzhauer, and K. Frankena. 2014. A descriptive review of the prevalence and risk factors of hock lesions in dairy cows. Vet. J. 202:222-228. https://doi.org/10.1016/j.tvjl.2014.07.004.

Olde Riekerink, R. G., K. van Amersfort, O. C. Sampimon, G. A. Hooijer, and T. Lam. 2014. Short communication: Prevalence, risk factors, and a field scoring system for udder cleft dermatitis in Dutch dairy herds. J. Dairy Sci. 97:5007-5011. https://doi.org/10 $.3168 /$ jds.2013-7651. 
Persson Waller, K. 2003. Nekrotisk dermatit framtill på juvret hos mjölkkor (Necrotic dermatitis at the front of the udder of dairy cows). Svensk Veterinärtidning 55:11-16. [In Swedish]

Persson Waller, K., M. Bengtsson, and A. K. Nyman. 2014. Prevalence and risk factors for udder cleft dermatitis in dairy cattle. J. Dairy Sci. 97:310-318. https://doi.org/10.3168/jds.2013-7186.

Potterton, S. L., M. J. Green, J. Harris, K. M. Millar, H. R. Whay, and J. N. Huxley. 2011. Risk factors associated with hair loss, ulceration, and swelling at the hock in freestall-housed UK dairy herds. J. Dairy Sci. 94:2952-2963. https://doi.org/10.3168/jds 2010-4084.

Stamm, L. V., R. L. Walker, and D. H. Read. 2009. Genetic diversity of bovine ulcerative mammary dermatitis-associated Treponema Vet. Microbiol. 136:192-196. https://doi.org/10.1016/j.vetmic .2008.10.022.

Växa Sverige. 2008. Avelsvärdering Version VIII. [Breeding evaluation Version VIII]. Accessed May 5, 2017. http://www.sweebv.info/ Dokument/Avelsv\%C3\%A4rdering\%20versionVIII.pdf.
Växa Sverige. 2017. Redogörelse för husdjursorganisationens Djurhälsovård 2015/2016. [Report on animal health care within the livestock organisation 2015/2016]. Accessed May 5, 2017. https:// www.vxa.se/globalassets/dokument/statistik/djurhalsovardens -arsredovisning_2015_16.pdf.

Warnick, L. D., D. Nydam, A. Maciel, C. L. Guard, and S. E. Wade. 2002. Udder cleft dermatitis and sarcoptic mange in a dairy herd J. Am. Vet. Med. Assoc. 221:273-276. https://doi.org/10.2460/ javma.2002.221.273.

Wolff, C., M. Espetvedt, A. K. Lind, S. Rintakoski, A. Egenvall, A. Lindberg, and U. Emanuelson. 2012. Completeness of the disease recording systems for dairy cows in Denmark, Finland, Norway and Sweden with special reference to clinical mastitis. BMC Vet. Res. 8:131. https://doi.org/10.1186/1746-6148-8-131. 